\title{
Tale of two complications following phakic intraocular lens implantation: secondary glaucoma and central serous retinopathy in one eye and inverted phakic IOL with cataract in the other eye
}

\author{
Raghav Preetam Peraka, ' Somasheila I Murthy (D) ,' Subhakar Reddy (D) , \\ Raja Narayanan (D) ${ }^{2}$
}

${ }^{1}$ Cornea and Anterior Segment Service, The Cornea Institute, LV Prasad Eye Institute, Hyderabad, Telangana, India

${ }^{2}$ Smt Kannuri Shantamma Retina Vitreous Service, LV Prasad Eye Institute, Hyderabad, Telangana, India

Correspondence to Dr Somasheila I Murthy; smurthy@lvpei.org

Accepted 30 September 2020

Check for updates

(c) BMJ Publishing Group Limited 2020. No commercial re-use. See rights and permissions. Published by BMJ.

To cite: Peraka RP, Murthy SI, Reddy $S$, et al. BMJ Case Rep 2020:13:e238300. doi:10.1136/bcr-2020238300

\section{DESCRIPTION}

A 25-year-old woman presented with a 6-month history of pain and decreased vision in both eyes. She had undergone bilateral phakic intraocular lens (IOL) implantation (implantable phakic contact lens (IPCL), V1.0, Care Group, Sight Solution, Vadodara, India) elsewhere 5 years earlier and was asymptomatic prior to this. For recurrent redness in the right eye (OD), she was started on topical and oral steroids and received two posterior subtenon injections of $20 \mathrm{mg} / 0.5 \mathrm{~mL}$ of triamcinolone acetonide 4 months ago for cystoid macular oedema. Subsequently, she was noted to have developed steroid-induced glaucoma and was on 1\% brinzolamide $/ 0.2 \%$ brimonidine eye drops twice a day. Visual acuity in OD was 20/30 (20/20 with glasses) and in left eye (OS) was 20/60, improving to $20 / 25$. Anterior chambers were quiet and IPCL was well-positioned in OD (figure 1A,B). OS showed paracentral anterior subcapsular cataract (figure 1C,D). Intraocular pressures were normal. Gonioscopy showed bilateral dense trabecular pigments, open angles in OD and peripheral anterior synechiae with three-quadrant angle closure in OS.

Vertical cup-to-disc ratio was 0.7:1 in OD; visual fields showed incomplete biarcuate scotoma. Macula of OD showed blunted foveal reflex, domeshaped elevation and multiple cystic spaces.

Anterior segment optical coherence tomography (AS-OCT) (Optovue, Fremont, California, USA) showed adequate vault in OD (figure 2A), and inverted IPCL, lens touch and localised cataract in OS (figure 2B). Macular OCT of OD revealed foveal neurosensory detachment, shaggy photoreceptors, pachyvessels and intraretinal schisis (figure 2C), and OS was normal (figure 2D). Specular microscopy showed counts of 2984 cells $/ \mathrm{mm}^{2}$ in OD and 1442 cells $/ \mathrm{mm}^{2}$ in OS. She was diagnosed with resolved uveitis with steroid-induced glaucoma in $\mathrm{OD}$, and resolving central serous retinopathy (CSR) and inverted IPCL and cataract in OS. Timolol eye drops twice daily was added for OD, and oral steroids were tapered. She was advised to undergo explantation of IPCL and cataract surgery in OS but she did not undergo the procedure because she preferred to get it done locally in her town.

Phakic IOLs show excellent results in moderateto-high myopia. ${ }^{1}$ IPCL demonstrated efficacy and
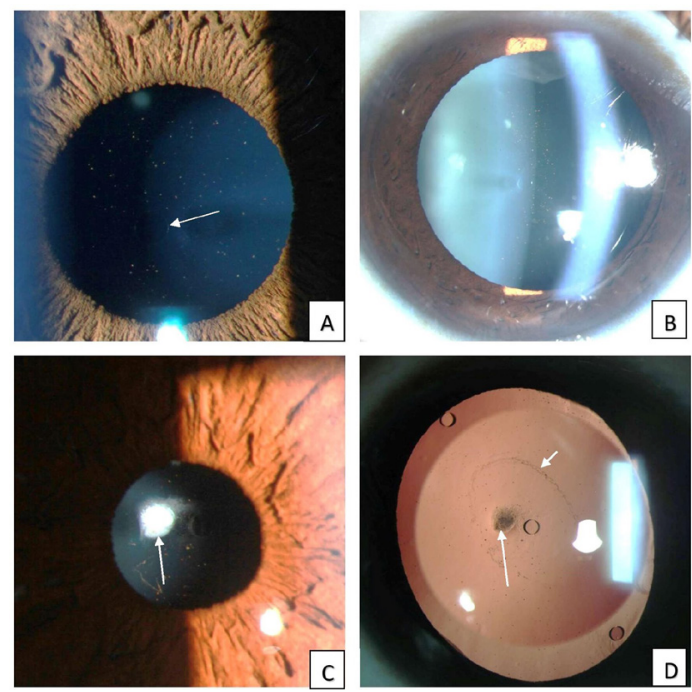

Figure 1 (A) Slit-lamp photograph of OD shows a well-positioned IPCL (central hole indicated by the white arrow). Some pigment is visible on the optic's surface. (B) OD, dilated view. (C) Slit-lamp photograph of the left eye shows IPCL with anterior subcapsular cataract (arrow). (D) After pupillary dilatation, the IPCL is noted to be inverted with a zone of contact on the lens capsule (short arrow) and paracentral cataract (long arrow). IPCL, implantable phakic contact lens; OD, right eye.

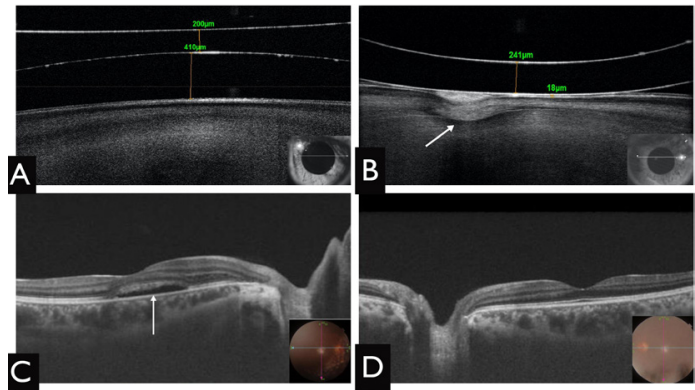

Figure 2 (A) AS-OCT of the right eye shows adequate vault of $400 \mu \mathrm{m}$. (B) In the left eye, OCT shows obliterated vault and an inverted IPCL, which is in contact with the anterior lens capsule. Arrow points to the cataractous portion (C) Macular OCT of the right eye shows neurosensory detachment (arrow) at the fovea. (D) Macular scan of the left eye is normal. AS-OCT, anterior segment optical coherence tomography; IPCL, implantable phakic contact lens. 
safety similar to Visian implantable collamer lens. ${ }^{2}$ Complications, though rare, can be related to lens sizing. Large-sized lenses can cause high vault and iris chafing, leading to recurrent uveitis. Incorrect orientation while inserting the lens is a known complication. Inverted lens will cause a low vault and anterior polar cataract in a stellate pattern. ${ }^{3}$ Though rare, this was known to occur with the V1.0 version of IPCL due to incorrect loading technique, intraoperative flipping or failure to recognise the incorrect side after injection. The newer version, IPCL V2.0, has a special patterned hole on the leading left corner to ensure correct orientation and positioning of IPCL. AS-OCT is invaluable in identifying the vault and inversion of phakic IOLs, as in our case. ${ }^{4}$ Removal of an inverted lens is necessary to prevent further complications such as secondary glaucoma and cataract

\section{Learning points}

- Inverted implantable phakic contact lens (IPCL) is an inadvertent and rare intraoperative complication and the surgeon should be familiar with the various tips for correct insertion

- If a very low vault is noted postoperatively, the possibility of inverted lens should be considered, and examination should be repeated after dilating the pupil.

- Anterior segment optical coherence tomography is a useful modality to measure the vault height and study the orientation of IPCL with respect to crystalline lens and to confirm inverted lens.

- Inverted phakic intraocular lens eventually need to be explanted to avoid further complications such as secondary glaucoma, chronic uveitis and progressive cataracts. progression. $^{5}$ Our patient had a series of unfortunate events in $\mathrm{OD}$; she had chronic postoperative inflammation, perhaps due to IPCL position shift over time, leading to macular oedema and steroid-induced glaucoma, leading to steroid-induced CSR. These are additional confounding factors.

Acknowledgements Hyderabad Eye Research Foundation.

Contributors RPP and SIM have conceptualised the work, drafted the manuscript and acquired the data. SIM has also treated the patient and revised the final manuscript. SR has acquired the data and analysed the same and contributed to the draft. RN has been involved in the management of the patient and review of the final draft.

Funding The authors have not declared a specific grant for this research from any funding agency in the public, commercial or not-for-profit sectors.

Competing interests None declared.

Patient consent for publication Obtained.

Provenance and peer review Not commissioned; externally peer-reviewed.

\section{ORCID iDs}

Somasheila I Murthy http://orcid.org/0000-0002-8696-9669

Subhakar Reddy http://orcid.org/0000-0001-5683-7334

Raja Narayanan http://orcid.org/0000-0001-9688-5859

\section{REFERENCES}

1 Moya T, Javaloy J, Montés-Micó R, et al. Implantable collamer lens for myopia: assessment 12 years after implantation. J Refract Surg 2015;31:548-56.

2 Sachdev GS, Singh S, Ramamurthy S, et al. Comparative analysis of clinical outcomes between two types of posterior chamber phakic intraocular lenses for correction of myopia and myopic astigmatism. Indian J Ophthalmol 2019;67:1061.

3 Gonvers M, Othenin-Girard P, Bornet C, et al. Implantable contact lens for moderate to high myopia: short-term follow-up of 2 models. J Cataract Refract Surg 2001:27:380-8.

4 Alfonso JF, Fernández-Vega-Cueto L, Alfonso-Bartolozzi B, et al. Five-Year follow-up of correction of myopia: posterior chamber phakic intraocular lens with a central Port design. J Refract Surg 2019;35:169-76.

5 Sanders DR, ICL in Treatment of Myopia Study Group. Postoperative inflammation after implantation of the implantable contact lens. Ophthalmology 2003;110:2335-41.

Copyright 2020 BMJ Publishing Group. All rights reserved. For permission to reuse any of this content visit

https://www.bmj.com/company/products-services/rights-and-licensing/permissions/

BMJ Case Report Fellows may re-use this article for personal use and teaching without any further permission.

Become a Fellow of BMJ Case Reports today and you can:

- Submit as many cases as you like

- Enjoy fast sympathetic peer review and rapid publication of accepted articles

- Access all the published articles

Re-use any of the published material for personal use and teaching without further permission

Customer Service

If you have any further queries about your subscription, please contact our customer services team on +44 (0) 2071111105 or via email at support@bmj.com.

Visit casereports.bmj.com for more articles like this and to become a Fellow 